\section{A proposed mechanism to explain increases in intracranial pressure: The concept of cerebral artery wedge}

\section{pressure}

\author{
DR Hamilton ${ }^{1 *}$, A Mitha ${ }^{2}$, MG Hamilton ${ }^{3}$ and JV Tyberg ${ }^{4}$ \\ ${ }^{1}$ Department of Internal Medicine, University of Calgary, Canada \\ ${ }^{2}$ Department of Clinical Neurosciences, University of Calgary, Canada \\ ${ }^{3}$ Department of Neurosurgery, University of Calgary, Canada \\ ${ }^{4}$ Department of Physiology and Pharmacology, Cumming School of Medicine, University of \\ Calgary, Canada
}

\section{Abstract}

We hypothesize that, with elevated cerebral spinal fluid (CSF) pressure, cerebral microvascular obstruction and congestion may occur despite (subdural) large-vein pressures being normal. Smaller veins emptying into these larger, dura-enveloped veins are not immune to the compressive effects of elevated CSF pressure and a "Starling Resistor" mechanism might explain why elevated CSF pressures collapse these smaller veins. This small cerebral venous starling resistor compression mechanism may be the final common pathway for many patients suffering from increased CSF pressures and might also be an important contributor to impaired focal venous drainage presenting as a headache with normal venous sinus pressures.

\section{More Information}

*Address for Correspondence: Douglas $\mathrm{R}$ Hamilton, Clinical Associate Professor, Medicine, Adjunct Professor, Electrical Engineering General Internal Medicine, University of Calgary, Calgary, Alberta, Canada, Email: doctorhami@gmail.com

Submitted: 21 November 2019

Approved: 07 January 2020

Published: 08 January 2020

How to cite this article: Hamilton DR, Mitha A, Hamilton MG, Tyberg JV. A proposed mechanism to explain increases to explain increases in intracranial pressure: The concept of cerebral artery wedge pressure.

J Cardiol Cardiovasc Med. 2020; 5: 001-003.

DOI: dx.doi.org/10.29328/journal.jccm.1001076

Copyright: ( 2020 Hamilton DR, et al. This is an open access article distributed under the Creative Commons Attribution License, which permits unrestricted use, distribution, and reproduction in any medium, provided the original work is properly cited.

Keywords: Coronary artery bypass grafting; Longitudinal strain; Right ventricle; Circumferential strain

\section{(T) Check for updates}

(d) OPEn Access

\section{Introduction}

Some patients suffer from the signs and symptoms of elevated cerebrospinal fluid (CSF) pressure, even though pressure measured in the cerebral venous system is normal.

We hypothesize that, with elevated CSF pressure, cerebral micro-vascular obstruction and congestion may occur, even though (subdural) large-vein pressures have been shown to be normal.

Idiopathic intracranial hypertension (IIH) can manifest itself with headache, papilledema, visual field changes and tinnitus with elevated cerebral spinal fluid opening pressures on lumbar puncture. If this condition is left untreated, itcan lead to permanent visual loss and debilitating chronic headaches. Previous treatment modalities include medical management, therapeutic lumbar puncture, cerebral-peritoneal shunting and optic nerve sheath fenestration. These treatments have enjoyed some effectiveness but carry high rates of symptom recurrence and/or procedural complications. Focal dural venous sinus stenoses have been identified in many patients with IIH, leading to development of treatment through venous sinus angioplasty and stenting. Puffer, et al., conducted a review of 143 patients ( $87 \%$ women, mean age 41.4 years, mean body mass index $31.6 \mathrm{~kg} / \mathrm{m}^{2}$ ) with $\mathrm{IIH}$ treated with venous sinus stenting. Symptoms at initial presentation included headache (90\%), papilledema (89\%), visual changes (62\%) and pulsatile tinnitus (48\%). At follow-up (mean 22.3 months), $88 \%$ of patients experienced improvement in headache, $97 \%$ demonstrated improvement or resolution of papilledema, $87 \%$ experienced improvement or resolution of visual symptoms and $93 \%$ had resolution of pulsatile tinnitus. In this cohort of patients with IIH with demonstrable focal venous sinus stenosis, endovascular stent placement across the stenotic sinus region was an effective treatment.

The pathophysiology of IIH is still controversial since many patients present with normal venous anatomy. Nonetheless intracranial venous hypertension leading to decreased CSF reabsorption has suggested to being the final common pathway in IIH [1-3]. It is well known that venous sinus thrombosis can produce IIH symptoms. The very high incidence of bilateral transverse-sigmoid junction stenosis seen on digital subtraction angiography and magnetic 
resonance venography led King, et al. [4], in 1995 to perform retrograde venography and manometric sinus pressure measurements in patients with IIH. They consistently found stenosis at the lateral aspect of both transverse sinuses and a concurrent pressure gradient. These findings have shed new light on a potential pathophysiologic mechanism behind IIH, but have raised questions as to whether the focal stenosis is causing the increased ICP, or if the stenosis is itself a secondary phenomena of increased ICP. A positive feedback mechanism must exist which, no matter what precipitates the focal stenosis, venous hypertension proximal to the stenotic area leads to further increased ICP causing continued or worsening stenosis, and impaired CSF drainage [2]. These pathophysiological mechanisms seem to adequately explain the evolution of IIH in patients with obvious intracranial venous stenosis. It still does not explain the findings of IIH in patients with totally patent veins seen using digital subtraction angiography and magnetic resonance venography.

How might these apparently incompatible observations be explained? At the outset, one must recognize that it has been tacitly and universally assumed that the pressure measured in dural veins (e.g., sagittal sinus) faithfully reflects upstream venous pressure and provides an accurate indication of CSF pressure. While it is easy to understand why this should be assumed, it might not be so because of the unique anatomy of intracranial veins. The largest veins and sinuses are so enveloped by the dura that they are "tented" open, practically regardless of variations in CSF pressure. Being thus held open, catheters passed upstream from the external jugular vein into the superior sagittal sinus will record a pressure commensurate with downstream venous pressure. However, this pressure may not be also commensurate with upstream venous pressure or be a useful indicator of elevated CSF pressure. Smaller veins emptying into these larger, duraenveloped veins are not immune to the compressive effects of elevated CSF pressure and a "Starling Resistor" [5], mechanism might explain why elevated CSF pressures collapse these smaller veins. If blood is to continue to flow, pressure upstream to the point of collapse must be greater than the CSF occluding pressure and this elevated small-vein/ capillary pressure might be the cause of headache, visual symptoms, etc.

How might this hypothesis be tested? As cardiologists appreciate well, occluding an artery with a balloon catheter will allow measurement of a downstream pressure via the end-hole of the catheter (e.g., the "Swan-Ganz" catheter in a branch of the pulmonary artery provides a measurement of left atrial pressure [6,7]). Likewise, if a small balloon catheter were to be placed in a middle cerebral artery, for example, arterial pressure would be measured before balloon inflation, but downstream venous pressure would be measured after inflation.
As illustrated in figure 1, when CSF pressure is normal (solid lines), this balloon-inflated pressure would be similar to sagittal sinus pressure. However, when CSF pressure is elevated (dashed lines), this balloon-inflated pressure would be higher than sagittal sinus pressure and equal to CSF pressure.

\section{Control observations (solid lines)}

Mean cerebral artery pressure:

$\sim 80 \mathrm{mmHg}$

Mean cerebral artery "wedge pressure":

$\sim 10 \mathrm{mmHg}$

CSF pressure:

$\sim 10 \mathrm{mmHg}$

Large-vein pressure:

$\sim 10 \mathrm{mmHg}$

After increasing CSF pressure to $35 \mathrm{mmHg}$ by adding volume (dashed lines)

Mean cerebral artery pressure: $\sim 80 \mathrm{mmHg}$

Mean cerebral artery "wedge pressure":

$\sim 35 \mathrm{mmHg}$

CSF pressure:

$\sim 35 \mathrm{mmHg}$

Large-vein pressure: $\sim 10 \mathrm{mmHg}$

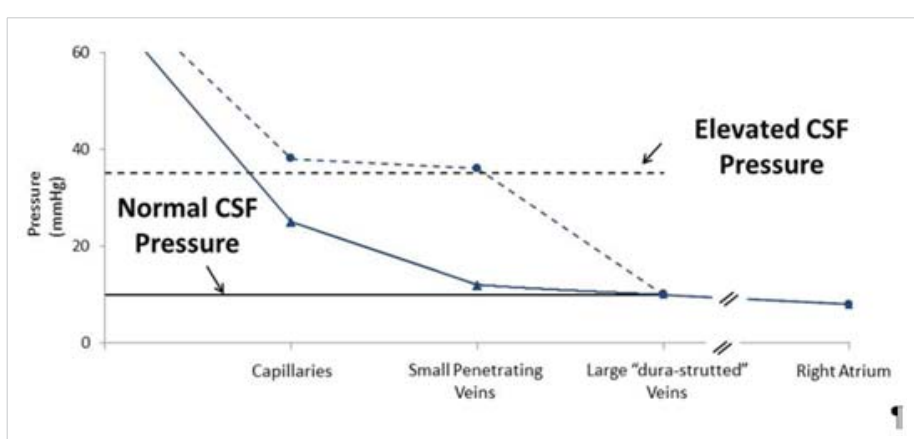

Figure 1: Control observations (solid lines). After increasing CSF pressure to 35 $\mathrm{mmHg}$ by adding volume (dashed lines)

Attempts to test this hypothesis in different species of experimental animals have, so far, been unsuccessful because so many animals have an extensive rete mirabile [8.9], upstream from their central intracranial arterial circulation that prevents the introduction of current technology balloon catheters.

We propose that this small cerebral venous starling resistor compression mechanism may be the final common pathway for many patients suffering from raised CSF pressures and could also be an important contributor to impaired focal venous drainage presenting as a headache with normal sinus fluid pressures.

\section{References}

1. Friedman DI. Cerebral venous pressure, intra-abdominal pressure, and dural venous sinus stenting in idiopathic intracranial hypertension. $J$ Neuroophthalmol. 2006; 26: 61-64.

PubMed: https://www.ncbi.nlm.nih.gov/pubmed/16518170

2. Albuquerque $F C$, Dashti $S R$, Hu YC, Newman $C B$, Teleb $M$, et al Intracranial venous sinus stenting for benign intracranial hypertension: clinical indications, technique, and preliminary results. World neurosurg. 2011; 75: 648-652.

PubMed: https://www.ncbi.nlm.nih.gov/pubmed/21704931 
3. Johnston I,Paterson A. Benign intracranial hypertension. II. CSF pressure and circulation. Brain: 1974; 97: 301-12.

PubMed: https://www.ncbi.nlm.nih.gov/pubmed/4434179

4. King JO, Mitchell PJ, Thomson KR, Tress BM. Cerebral venography and manometry in idiopathic intracranial hypertension. Neurology. 1995; 45: 2224-2228.

PubMed: https://www.ncbi.nlm.nih.gov/pubmed/8848197

5. Magder S. Starling resistor versus compliance. Which explains the zero-flow pressure of a dynamic arterial pressure-flow relation? Circulation res. 1990; 67: 209-220.

PubMed: https://www.ncbi.nlm.nih.gov/pubmed/2364491

6. Swan HJ, Ganz W, Forrester J, Marcus H, Diamond G, et al Catheterization of the heart in man with use of a flow-directed balloon- tipped catheter. N Engl J Med. 1970; 283: 447-451.

PubMed: https://www.ncbi.nlm.nih.gov/pubmed/5434111

7. Kubiak GM, Ciarka A, Biniecka M, Ceranowicz P. Right Heart Catheterization-Background, Physiological Basics, and Clinical Implications. J Clin Med. 2019; 8. E1331.

PubMed: https://www.ncbi.nlm.nih.gov/pubmed/31466390

8. Daniel PMD, JD, Prichard MM. Studies of the Carotid Rete and Its Associated Arteries. Phil Trans Roy Soc London. 1953; 237: 173-208.

9. Wang $\mathrm{H}, \mathrm{Kim} \mathrm{M}$, Normoyle KP, Llano D. Thermal Regulation of the BrainAn Anatomical and Physiological Review for Clinical Neuroscientists. Front Neurosci. 2015; 9: 528.

PubMed: https://www.ncbi.nlm.nih.gov/pubmed/26834552 